\title{
EHMTI-0307. Chronification of migraine: a clinical and voxel-based morphometry study
}

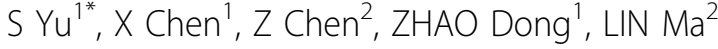 \\ From 4th European Headache and Migraine Trust International Congress: EHMTIC 2014 \\ Copenhagen, Denmark. 18-21 September 2014
}

\section{Introduction}

Migraine is an episodic disease which may transform to a chronic form. However, the precise pathogenesis of migraine chronification is not well understood.

\section{Aim}

We aimed to detect the changes of brain gray matter volume (GMV) in chronification of migraine.

\section{Methods}

Voxel-based morphometry (VBM) of MRI was employed to analyze the volume of brain gray matter in 44 patients with chronic migraine with medication-overuse headache (CM-MOH), 16 patients with $\mathrm{CM}$ without $\mathrm{MOH}$ $(\mathrm{CMwoMOH}), 18$ patients with episodic migraine (EM) and 32 healthy controls (HCs).

\section{Results}

The GMV did not differ significantly among groups but was positively related to body mass index (BMI) and male gender, negatively related to age, course of disease and anxiety. Compared with HCs, local GMV of middle temporal pole decreased in all the three patient groups. GMV of right superior and middle orbitofrontal gyrus and right inferior temporal gyrus decreased in $\mathrm{CM}-\mathrm{MOH}$ and CMwoMOH groups. Besides, GMV of left gyrus rectus, middle cingulate gyrus, bilateral insula, right Rolandic Operum, occipital lobes decreased in $\mathrm{CM}-\mathrm{MOH}$ group. GMV of right middle frontal gyrus, Rolandic Operum, right precentral gyrus, left postcentral gyrus, left superior occipital lobe increased in patients with EM and $\mathrm{CMwoMOH}$. Furthermore, $\mathrm{CMwoMOH}$ patients had significantly increased GMV in bilateral caudate nucleus.

${ }^{1}$ Department of Neurology, Chinese PLA General Hospital, Beijing, China Full list of author information is available at the end of the article

\section{Conclusion}

Our findings indicate that a reduced volume of orbitofrontal gyrus may reflect chronicty of migraine. Decreased GMV of gyrus rectus may reflect disease-specific modifications of $\mathrm{CM}-\mathrm{MOH}$. Increased GMV of caudate nucleus may specifically reflect pathophysiological changes of chronicity of migraine without medication overuse.

No conflict of interest.

\section{Authors' details}

${ }^{1}$ Department of Neurology, Chinese PLA General Hospital, Beijing, China.

2Department of Radiology, Chinese PLA General Hospital, Beijing, China.

Published: 18 September 2014

doi:10.1186/1129-2377-15-S1-E43

Cite this article as: Yu et al.: EHMTI-0307. Chronification of migraine: a clinical and voxel-based morphometry study. The Journal of Headache and Pain 2014 15(Suppl 1):E43.

\section{SpringerOpen $^{\circ}$}

(c) 2014 Yu et al; licensee Springer. This is an Open Access article distributed under the terms of the Creative Commons Attribution License (http://creativecommons.org/licenses/by/2.0), which permits unrestricted use, distribution, and reproduction in any medium, provided the original work is properly cited.
Submit your manuscript to a SpringerOpen ${ }^{\circ}$ journal and benefit from:

- Convenient online submission

- Rigorous peer review

- Immediate publication on acceptance

- Open access: articles freely available online

- High visibility within the field

Retaining the copyright to your article 